\title{
OSBPL2 encodes a protein of inner and outer hair cell stereocilia and is mutated in autosomal dominant hearing loss (DFNA67)
}

Michaela Thoenes ${ }^{1}$, Ulrike Zimmermann ${ }^{2}$, Inga Ebermann ${ }^{1}$, Martin Ptok ${ }^{3}$, Morag A Lewis ${ }^{4}$, Holger Thiele ${ }^{5}$, Susanne Morlot ${ }^{6}$, Markus M Hess ${ }^{7}$, Andreas Gal ${ }^{8}$, Tobias Eisenberger ${ }^{9}$, Carsten Bergmann ${ }^{9,10}$, Gudrun Nürnberg ${ }^{5}$, Peter Nürnberg ${ }^{5,11}$, Karen P Steel ${ }^{4}$, Marlies Knipper ${ }^{2}$ and Hanno Jörn Bolz ${ }^{1,9^{*}}$

\begin{abstract}
Background: Early-onset hearing loss is mostly of genetic origin. The complexity of the hearing process is reflected by its extensive genetic heterogeneity, with probably many causative genes remaining to be identified. Here, we aimed at identifying the genetic basis for autosomal dominant non-syndromic hearing loss (ADNSHL) in a large German family.

Methods: A panel of 66 known deafness genes was analyzed for mutations by next-generation sequencing (NGS) in the index patient. We then conducted genome-wide linkage analysis, and whole-exome sequencing was carried out with samples of two patients. Expression of Osbpl2 in the mouse cochlea was determined by immunohistochemistry. Because Osbp/2 has been proposed as a target of miR-96, we investigated homozygous Mir96 mutant mice for its upregulation.

Results: Onset of hearing loss in the investigated ADNSHL family is in childhood, initially affecting the high frequencies and progressing to profound deafness in adulthood. However, there is considerable intrafamilial variability. We mapped a novel ADNSHL locus, DFNA67, to chromosome 20q13.2-q13.33, and subsequently identified a co-segregating heterozygous frameshift mutation, c.141_142delTG (p.Arg50Alafs*103), in OSBPL2, encoding a protein known to interact with the DFNA1 protein, DIAPH1. In mice, Osbpl2 was prominently expressed in stereocilia of cochlear outer and inner hair cells. We found no significant Osbp/2 upregulation at the mRNA level in homozygous Mir96 mutant mice.

Conclusion: The function of OSBPL2 in the hearing process remains to be determined. Our study and the recent description of another frameshift mutation in a Chinese ADNSHL family identify OSBPL2 as a novel gene for progressive deafness.
\end{abstract}

Keywords: OSBPL2, DFNA67, Autosomal dominant hearing loss

\section{Background}

Hearing impairment is the most common sensory disorder, affecting approximately $1 / 500$ newborns. In developed countries, most cases are of genetic origin, and there is extensive allelic and non-allelic heterogeneity. In $70 \%$ of hearing-impaired neonates, the sensory deficit is non-syndromic (non-syndromic hearing loss,

\footnotetext{
* Correspondence: hanno.bolz@bioscientia.de

'Institute of Human Genetics, University Hospital of Cologne, Cologne, Germany

${ }^{9}$ Center for Human Genetics, Bioscientia, Ingelheim, Germany

Full list of author information is available at the end of the article
}

NSHL). Approximately 20\% of patients have autosomal dominantly-inherited forms (ADNSHL) and typically display postlingual progressive hearing impairment. Sixty-five ADNSHL loci have been officially designated, and 30 causative genes have been reported [1-3]. Because of the extensive genetic heterogeneity of hearing impairment, the identification of the causative mutation in single patients has been the exception until recently. With the advent of next-generation sequencing (NGS), deafness genes have become accessible to comprehensive genetic analysis and routine genetic testing by targeted NGS of "gene panels" [4].

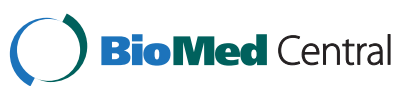

(C) 2015 Thoenes et al.; licensee BioMed Central. This is an Open Access article distributed under the terms of the Creative Commons Attribution License (http://creativecommons.org/licenses/by/4.0), which permits unrestricted use, distribution, and reproduction in any medium, provided the original work is properly credited. The Creative Commons Public Domain Dedication waiver (http://creativecommons.org/publicdomain/zero/1.0/) applies to the data made available in this article, unless otherwise stated. 


\section{Methods \\ Patients}

Samples of the German family reported herein (Figure 1) were obtained with written informed consent. Clinical investigations were conducted according to the Declaration of Helsinki, and the study was approved by the institutional review board of the Ethics Committee of the University Hospital of Cologne. The affected subjects underwent detailed audiological evaluations (e.g., pure tone audiometric air conduction, bone conduction, speech reception threshold, otoacoustic emissions, and impedance audiometry, phoneme discrimination), except IV:12 who reports intermittent hearing impairment (related to stress). Following the recommendations of the $\mathrm{EU}$ HEAR project [5], hearing loss was classified as mild $(20-40 \mathrm{~dB})$, moderate $(41-70 \mathrm{~dB})$, severe $(71-95 \mathrm{~dB})$, or profound $(>95 \mathrm{~dB})$. This classification, however, was difficult in some cases, because at least two patients $(\mathrm{V}: 2, \mathrm{~V}: 3)$ had near normal hearing in the $250-1000 \mathrm{~Hz}$ region, but a loss of about $70-90 \mathrm{~dB}$ in the higher frequencies.

GJB2 analysis and targeted NGS of a deafness gene panel The GJB2 gene was directly sequenced in the index patient, IV:10. His sample was then subjected to NGS for 66 genes (1,259 coding exons) that have been associated with NSHL and selected forms of SHL on a MiSeq system (Illumina) as described previously [6]. In brief, sheared DNA was ligated to bar-coded adaptors for multiplexing. Exons were targeted by an in-solution customized sequence capture library (NimbleGen). Amplified enriched DNA was directly subjected to NGS (MiSeq). Reads were mapped against the hg19 human reference genome using BWA [7] and processed with
SAMtools [8], Picard (http://broadinstitute.github.io/picard/) and GATK [9]. Variants were filtered against dbNSFP v2.0 [10], dbSNP v137, the Human Gene Mutation Database (HGMD ${ }^{\circ}$ Professional 2013.2) [11] and our in-house database. The cutoff for the maximum minor allele frequency (MAF) was set to 1\% [12]. Nonsense, frameshift and canonical splice site variants were regarded likely pathogenic. SNVs were assessed using SIFT [13], Mutation Taster [14], PolyPhen-2 [15], AlignGVGD [16,17], Pmut [18], NNSPLICE v0.9 [19] and NetGene2 [20,21]. SeqPilot SeqNext module (v4.0.1, JSI medical systems) was used for visualization and final assessment of SNVs.

\section{Linkage analysis and locus designation}

DNA samples from seven affected and six unaffected members of the family (Figure 1) were genotyped using the Affymetrix GeneChip Human Mapping $10 \mathrm{~K}$ SNP array Xba142. The gender was verified by counting heterozygous single nucleotide polymorphisms (SNPs) on the X chromosome. Relationship errors were evaluated with the help of the program Graphical Representation of Relationships [22]. Linkage analysis was performed assuming autosomal dominant inheritance, full penetrance, and a disease gene frequency of 0.0001. Multipoint LOD scores were calculated using the program ALLEGRO [23]. Haplotypes were reconstructed with ALLEGRO and presented graphically with HaploPainter [24]. All data handling was performed using the graphical user interface ALOHOMORA [25].

Following the identification of the causative mutation in OSBPL2, DFNA67 was assigned as a novel locus designation for ADNSHL by the Human Gene Nomenclature Committee, HGNC.

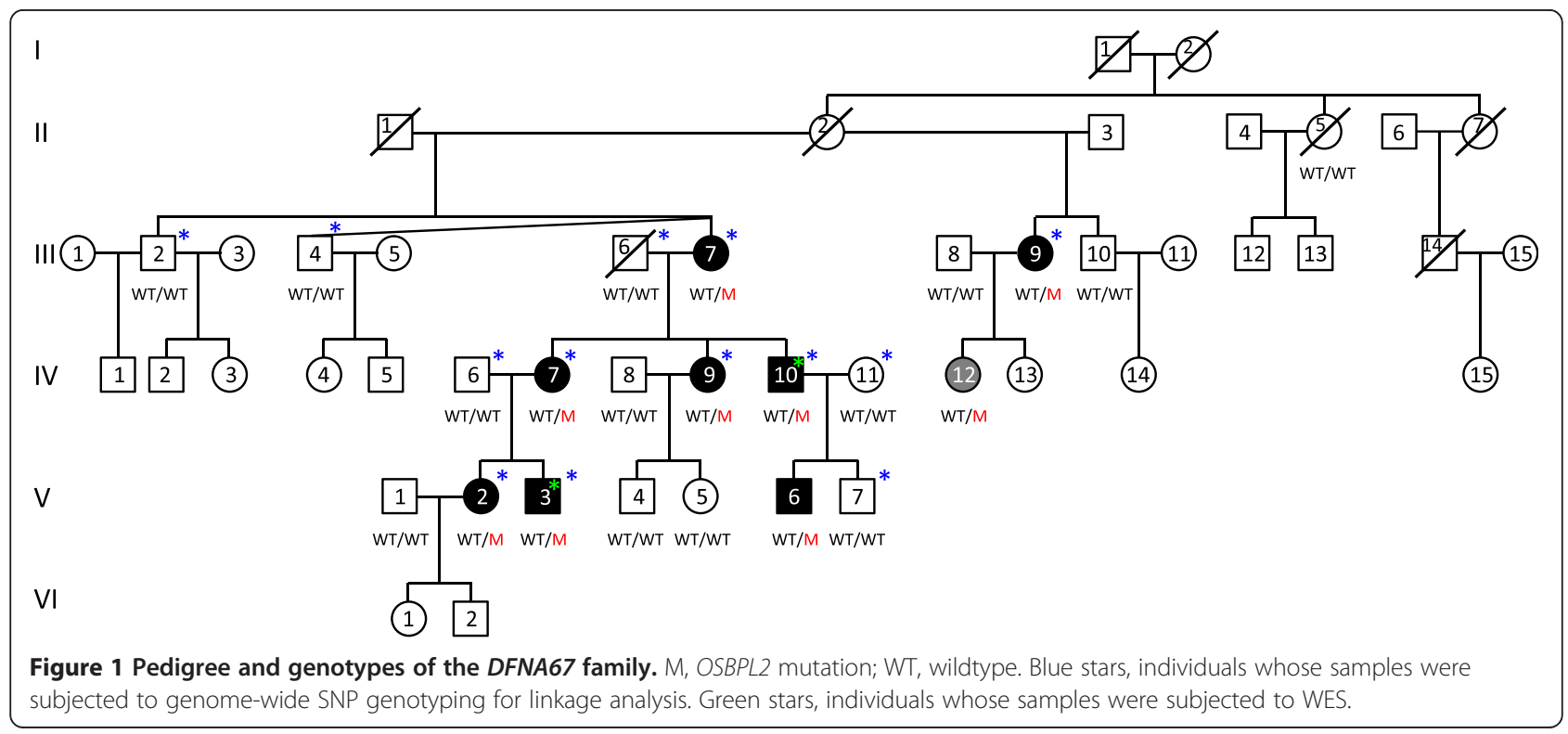




\section{Whole-exome sequencing}

Samples of two affected family members, IV:10 and V:3, were subjected to whole-exome sequencing (WES). DNA $(1 \mu \mathrm{g})$ was fragmented using sonication technology (Covaris). Fragments were enriched using the SeqCap EZ Human Exome Library v2.0 kit (Roche NimbleGen) and subsequently sequenced on an Illumina HiSeq 2000 sequencing instrument using a paired-end $2 \times 100$-bp protocol. This generated 6.1 and $8.2 \mathrm{~Gb}$ of mapped sequences with a mean coverage of 80 -fold and 101-fold, a 30 -fold coverage of $89 \%$ and $89 \%$ of the target sequences and a 10 -fold coverage of $96 \%$ and $95 \%$ of the target sequences. For data analysis, the Varbank pipeline (v.2.3) and filter interface was used (https://varbank.ccg.unikoeln.de). Primary data were filtered according to signal purity by Illumina Real-Time Analysis (RTA) software (v1.8). Subsequently, the reads were mapped to the human genome reference build hg19 using the bwa-aln alignment algorithm. GATK v1.6 [9] was used to mark duplicated reads, perform local realignment around short insertions and deletions, recalibrate the base quality scores, and call SNPs and short indels. Scripts developed in-house at the CCG were applied to variants predicted to result in protein changes, variants affecting donor and acceptor splice sites, and those overlapping with known variants. Acceptor and donor splice site mutations were analyzed with a maximum-entropy model and filtered for their putative effect on splicing. In particular, we focused on the linkage regions (chr12:49,329,157$52,752,362$ and chr20:52,882,032-61,366,354; hg19) and filtered for high-quality ( $>15$-fold coverage; quality $>25$; VQSR > -2), and for rare (MAF <0.005) and heterozygous variants. Several genome-wide databases (dbSNP Build 135, 1000 Genomes Project database build 20110521 [26] and the public Exome Variant Server, NHLBI, Seattle, build ESP6500 [27]) were checked for the presence of the identified variants. To exclude pipeline-related artifacts (MAF <0.005), we also filtered against an in-house database containing variants from 511 exomes of individuals with epilepsy. Finally, we filtered for variants present in both patients. Verification of sequence variants and segregation analyses were carried out by Sanger sequencing. Sequence data for OSBPL2 (MIM 606731) were compared to the reference sequence NM_144498.2.

\section{RT-PCR from cochlear tissue}

mRNA from mouse postnatal day 19 (P19) and rat P17 cochleae was isolated as described earlier [28]. A 298 bp fragment of Osbpl2 was amplified using the following primer sequences: 5' -CCAACTCTGCTCAGATGTACA AC-3' (forward) and 5'-GCTGTACGCCGGCCATTAC TTTGA-3' (reverse). PCR was performed with PuRe$\mathrm{Taq}^{\mathrm{TM}}$ Ready-To-Go ${ }^{\mathrm{TM}}$ PCR beads (GE Healthcare). The amplification conditions consisted of an initial denaturation phase of $94^{\circ} \mathrm{C}$ for $4 \mathrm{~min}, 35$ cycles of $30 \mathrm{~s}$ denaturation $\left(94^{\circ} \mathrm{C}\right), 30 \mathrm{~s}$ annealing $\left(58^{\circ} \mathrm{C}\right), 30 \mathrm{~s}$ extension $\left(72^{\circ} \mathrm{C}\right.$ ), and a final extension phase of $5 \mathrm{~min}$ at $72^{\circ} \mathrm{C}$. The PCR products were analyzed on ethidium bromide agarose gels. Fragments were extracted using QIAquick Gel Extraction Kit (Qiagen), cloned and sequenced.

\section{Tissue preparation and immunohistochemistry}

Cochleae from adult mice (aged between P20 and six months) were used to prepare cryosections for immunofluorescence microscopy. For immunohistochemistry on cryosections, the temporal bone of mature mice was dissected on ice and immediately fixed using Zamboni's fixative [29] containing picric acid by infusion through the round and oval window and incubated for 15 min on ice, followed by rinsing with phosphate-buffered saline (PBS) and decalcification in rapid bone decalcifier (Eurobio, Fisher-Scientific). After injection of 25\% sucrose in PBS, pH 7.4, cochleae were embedded in O.C.T. compound (Miles Laboratories, Elkhart, IN). Tissues were then cryosectioned at $10 \mu \mathrm{m}$ thickness, mounted on SuperFrost"/plus microscope slides, dried for $1 \mathrm{~h}$ and stored at $-20^{\circ} \mathrm{C}$ before use. Cryosections were thawed and permeabilized with $0.1 \%$ Triton X-100 (Sigma Aldrich) for $3 \mathrm{~min}$ at room temperature, blocked with 1\% BSA in PBS, and incubated with primary antibody in $0.5 \%$ BSA in PBS overnight at $+4^{\circ} \mathrm{C}$. For double labeling studies, specimens were simultaneously incubated with both antibodies for identical time periods. As primary antibodies we used: anti-ORP-2 (OSBPL2) antibody (goat, Santa Cruz Biotechnology, Inc., sc-66570, dilution 1:50), anti-prestin antibody (rabbit [30], dilution 1:5000), and anti-otoferlin antibody (rabbit [31], dilution 1:10000). Primary antibodies were detected with Cy3- (Jackson Immunoresearch Laboratories) and Alexa488- (Invitrogen, Life Technologies GmbH) conjugated secondary antibodies. Sections embedded with Vectashield mounting medium containing nuclear marker DAPI (Vector Laboratories). Sections were viewed using an Olympus BX61 microscope equipped with motorized $\mathrm{z}$-axis and epifluorescence illumination. To increase display resolution, cochlear slices were imaged over a distance of several micrometers $(30 \times 0,27 \mu \mathrm{m}, \sim 8 \mu \mathrm{m})$ in an image stack along the $\mathrm{z}$-axis (z-stack), followed by 3 dimensional deconvolution using cellSens Dimension module with the advanced maximum likelihood estimation algorithm (ADVMLE; OSIS). Images were acquired using a CCD camera and analyzed with cellSens software (Olympus Soft Imaging Solutions, OSIS). Images were processed with Photoshop.

\section{Comparison of Osbp/2 mRNA levels between wildtype and} homozygous Mir96 mutant diminuendo (Mir96 ${ }^{\text {Dmdo }}$ ) mice Organ of Corti dissection, RNA extraction and cDNA creation were carried out as described previously [32]. 
Primers were purchased from Applied Biosystems (Hprt1: Mm01318747_g1, Jag1: Mm01270190_m1, Osbpl2: Mm01 210488_m1). Hprt1 was used as an internal control, and Jag1, which is expressed in supporting cells [32-34], was used to control for the quantity of sensory tissue present. Pairs were only used when Jag1 levels did not differ significantly between wildtype and homozygote littermates $(\mathrm{p}>0.05)$. Three animals were genotyped and at least three technical replicates were performed on each pair. The reaction was run on a CFX Connect machine using Bio-Rad SsoFast and SsoAdvanced Master mixes (Bio-Rad Laboratories, cat. nos. 1725232, 1725281).

\section{Results}

\section{Clinical characterization of DFNA67 patients}

In most affected family members, bilateral sensorineural non-syndromic hearing loss was first noted in the early second decade of life and affected initially the high frequencies. However, the age of onset varied between 10 (patients IV:7, V:6) and 30 years of age (III:9). Real onset may have been earlier in many cases: Retrospectively, the parents of patient V:3 assume that hearing was already impaired around the age of 2 years. Progression of hearing loss was also widely variable. It was mild in younger individuals but severe to profound at later stages (Figure 2) and required cochlear implantation between 27 and 50 years of age in five family members. On the mild end of the spectrum, patient IV:10 noted onset of hearing loss at 22 years of age and started using hearing aids at 34 years. No audiological data were available for IV:12, a 39-years old carrier of the OSBPL2 mutation, who does not use hearing aids but claims worse hearing in stressful situations. III:7 and V:2 reported progression of hearing loss in the course of pregnancy and birth of children (see Table 1 for a summary of clinical data). Vestibular symptoms were not reported.

\section{Mapping of chromosomal candidate loci}

Using ALLEGRO we identifed two genomic regions with a maximum LOD score of 2.7. The obtained LOD score was the maximum possible LOD score in this family. We found linkage to a 3.4 Mb interval between SNPs rs1316607 and rs725029 on chromosome 12 $(49,329,157$ - 52,752,362) and to a $8.4 \mathrm{Mb}$ interval between rs2065042 and rs720607 on chromosome 20 $(52,882,032-61,366,354)$ (Figure 3 A).

\section{Targeted NGS, WES and segregation analysis of the candidate variants identified}

No mutation was identified in GJB2 and in subsequent targeted NGS of 66 known deafness genes. After stringent filtering of WES data, only two heterozygous variants remained that localized to the chromosome 12 candidate region: The c.1516C>G (p.Arg506Gly) variant in SLC11A2 has been annotated in dbSNP (rs199589052), but no MAF is available. Biallelic mutations in SLC11A2 cause autosomal recessive hypochromic microcytic anemia with iron overload but there is no mention of any hearing impairment [35]. It is therefore unlikely that heterozygous SLC11A2 mutations cause ADNSHL. A missense variant, c.53G>A (p.Arg18His), was identified in CELA1 (chymotrypsin-like elastase family, member 1 ). Because of its expression in skin tissue, CELA1 had been considered a candidate for skin disease. However, a common frameshift polymorphism questioned essentiality of this gene [36]. Moreover, the p.Arg18His variant has an MAF of $0.28 \%$ which is not compatible with a mutation causing a rare autosomal dominant disorder.

There were two heterozygous missense variants in genes contained in the candidate region on chromosome 20: The variant c.1202G $>C$ (p.Arg401Pro) in GTPBP5 affects an evolutionarily non-conserved residue and has been annotated as a polymorphism, rs200118420, with an MAF of $0.04 \%$. A variant in DIDO1 (c.1738A>C; p. Thr580Pro), also affects a non-conserved residue. Mutant Dido -/ and +/- mice appeared grossly normal. With time, some heterozygous mice showed abnormalities in spleen, bone marrow, and peripheral blood, overlapping with symptoms of myeloid dysplasia or myeloid proliferation [37]. Taken together, none of these three missense variants appeared to be a promising candidate for the ADNSHL-causing mutation.

A nonsense mutation, c. $287 \mathrm{C}>\mathrm{G}$ (p.Ser96*), was found in both patients in SLC17A9, a gene directly adjacent $(61,583,999-61,599,949)$ to the telomeric boundary of the chromosome 20 locus. According to the Exome Variant Server, the SLC17A9 nonsense variant has an MAF of $0.06 \%$, and compatible with the gene's localization just outside the candidate locus, it was carried by three healthy individuals of the family (II:5, III:10, IV:13). Moreover, p. Ser96" ${ }^{\text {SLC17A9 }}$ was also present in heterozygous state in three samples of our in-house database: A patient with epilepsy, a patient with amyotrophic lateral sclerosis and the healthy mother of that patient. None of these three individuals had hearing loss.

We identified only one truncating variant in a gene contained in a mapped candidate region: Both patients carried the frameshift mutation c.141_142delTG (p. Arg50Alafs*103) in OSBPL2 (Figure 3B,C), a gene from the chromosome 20 region. This variant has not been annotated in any of the above databases, no allele frequency is available, and it co-segregated perfectly with hearing loss in the family.

\section{Expression of Osbp/2 in the murine cochlea}

We analyzed the expression of Osbpl2 at the transcriptional level of post-hearing animals using RT-PCR with mRNA from whole mouse (P19) and rat (P17) cochlea. 
IV:7

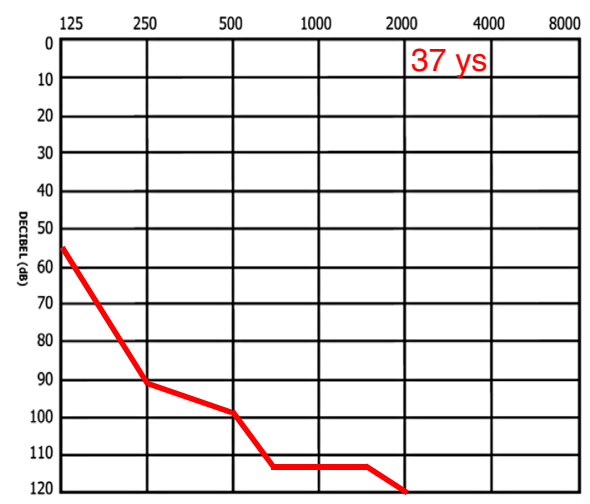

$\mathrm{IV}: 10$

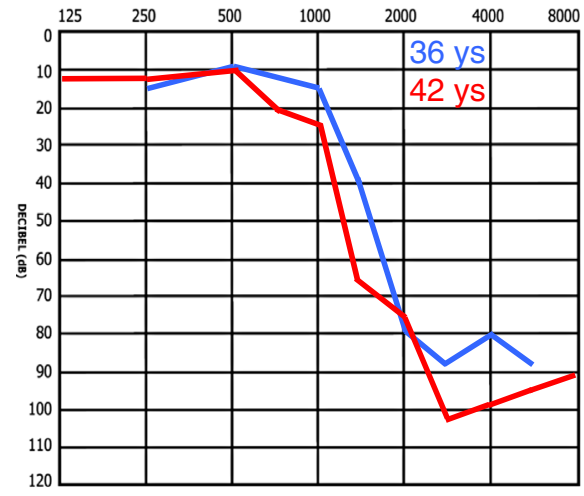

$\mathrm{V}: 3$

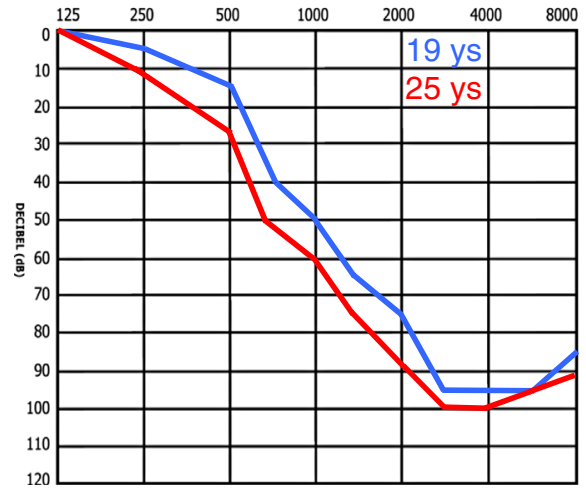

IV:9

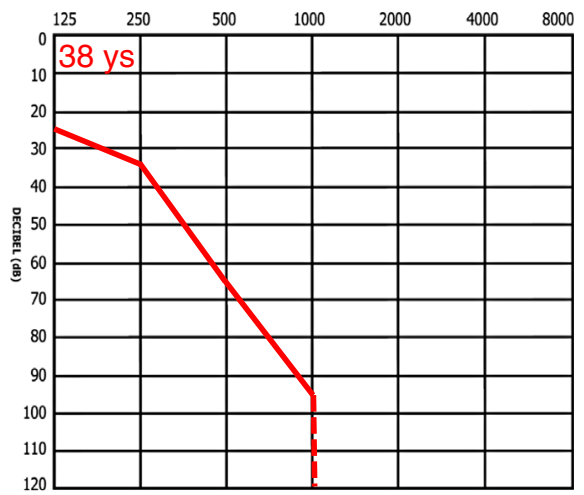

$\mathrm{V}: 2$

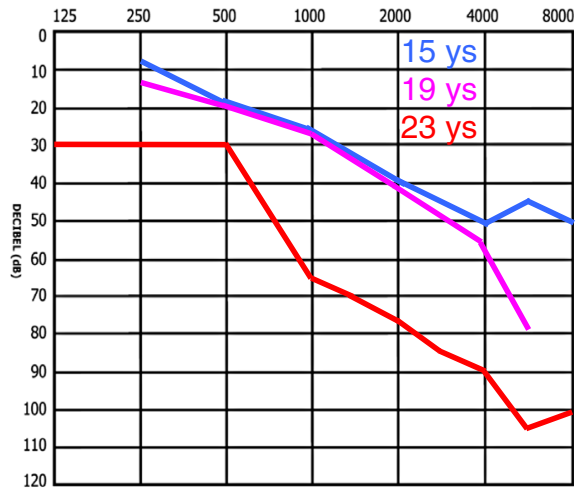

$\mathrm{V}: 6$

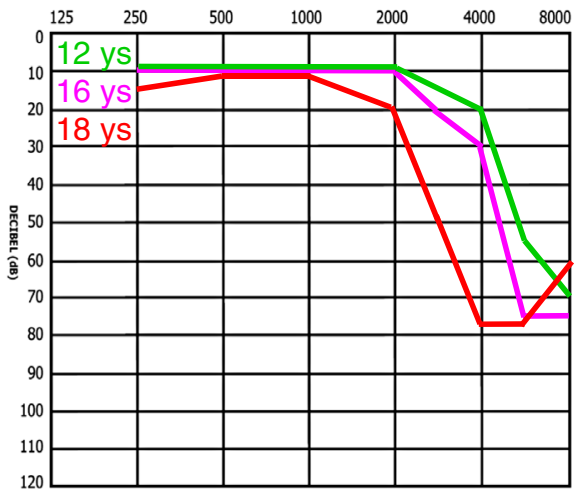

Figure 2 Exemplary audiograms of patients from the DFNA67 family. Hearing thresholds are shown for the more severely affected side.

The amplification product of Osbpl2 with the appropriate size (298 bp) was found in both mouse (Figure 3D, lane 2) and rat cochlea (Figure 3D; lane3). Next, we analyzed Osbpl2 expression in the organ of Corti of mice at the protein level using anti-Osbpl2 antibody in combination with either anti-prestin antibody used as an outer hair cell $(\mathrm{OHC})$ marker or anti-otoferlin antibody used as an inner hair cell (IHC) marker. Osbpl2 was detected in stereocilia of both OHCs (Figure 4A,B) and IHCs (Figure 4C,D). We found no difference in expression of Osbpl2 between P20 and 6-month-old mice (not shown).

\section{Comparison of Osbp/2 mRNA levels between wildtype and homozygous Mir96 mutant mice}

No significant difference was observed between wildtype and homozygote levels of Osbpl2 mRNA in the organ of Corti (Additional file 1).

\section{Discussion}

Mutations in approximately 30 genes have been implicated in ADNSHL (with variable evidence) [2]. The respective gene products fall into many different categories and comprise ion channels and transporters, 
Table 1 Summary of clinical data

\begin{tabular}{|c|c|c|c|c|c|}
\hline Individual & Age (ys.) & Hearing loss & Age of onset (ys.) & Course & OSBPL2 \\
\hline$\|: 1$ & $36(\dagger)$ & no & & & no sample \\
\hline$\|: 2$ & $69(\dagger)$ & $\begin{array}{l}\text { not noted by any of the five children, } \\
\text { but nasal pronunciation }\end{array}$ & $?$ & $?$ & no sample \\
\hline$\|: 5$ & $93(\dagger)$ & no & & & wildtype \\
\hline$\|: 7$ & $78(\dagger)$ & no & & & no sample \\
\hline\|\|$: 2$ & 76 & no & & & wildtype \\
\hline |II:4 & 71 & unilateral (untreated otitis media) & & & wildtype \\
\hline$\| 11: 6$ & $74(\dagger)$ & no & & & wildtype \\
\hline $111: 7$ & 71 & yes & 12 & $\begin{array}{l}\text { worse after birth of children, } \\
\text { stress; } \mathrm{Cl} \text { around } 50 \text { ys. }\end{array}$ & p.Arg50Alafs*103 \\
\hline$\|1\|: 8$ & 67 & no & & & wildtype \\
\hline$\| 11: 9$ & 61 & yes & 30 & $\mathrm{Cl}$ at $50 \mathrm{ys}$. & p.Arg50Alafs*103 \\
\hline$\|1\|: 10$ & 64 & $\begin{array}{l}\text { only temporary, episodes of acute } \\
\text { hearing loss }\end{array}$ & & & wildtype \\
\hline IV:6 & 58 & no & & & wildtype \\
\hline $\mathrm{IV}: 7$ & 50 & yes & 10 & $\mathrm{Cl}$ at 36 ys. & p.Arg50Alafs*103 \\
\hline $\mathrm{IV}: 8$ & 50 & no & & & wildtype \\
\hline IV:9 & 49 & yes & 12 & $\mathrm{Cl}$ at $39 \mathrm{ys}$. & p.Arg50Alafs*103 \\
\hline $\mathrm{V}: 10$ & 45 & yes & 22 & hearing aids at 34 ys. & p.Arg50Alafs*103 \\
\hline $\mathrm{IV}: 11$ & 44 & no & & & wildtype \\
\hline $\mathrm{IV}: 12$ & 39 & $\begin{array}{l}\text { no data from investigations; } \\
\text { hearing worse under stress }\end{array}$ & $?$ & $?$ & p.Arg50Alafs*103 \\
\hline IV:13 & 35 & no; two healthy daughters & & & no sample \\
\hline $\mathrm{V}: 2$ & 28 & yes & 15 & worsening after birth of children; $\mathrm{Cl}$ at $27 \mathrm{ys}$. & p.Arg50Alafs*103 \\
\hline $\mathrm{V}: 3$ & 26 & yes & 11 & hearing aids at $12 \mathrm{ys}$. & p.Arg50Alafs*103 \\
\hline $\mathrm{V}: 4$ & 15 & no & & & wildtype \\
\hline V:5 & 16 & no & & & wildtype \\
\hline $\mathrm{V}: 6$ & 20 & yes & 10 & hearing aids at $15 \mathrm{ys}$. & p.Arg50Alafs*103 \\
\hline $\mathrm{V}: 7$ & 17 & no & & & wildtype \\
\hline Vl:1 & 3 & no (normal OAEs at 3 ys.) & & & wildtype \\
\hline $\mathrm{Vl}: 2$ & 4 months & no & & & \\
\hline
\end{tabular}

motor molecules, components of the extracellular matrix, the cytoskeleton, adhesion complexes etc. [1].

Of the five heterozygous variants found in genes from the mapped candidate regions on chromosomes 12 and 20 in our family, the OSBPL2 frameshift mutation represented a reasonable candidate for the ADNSHL-causing mutation (see results section). OSBPL2 does not belong to any of the above protein classes. It is part of a 12member, evolutionarily highly conserved family of lipid binding/transfer proteins, the oxysterol binding proteins (OSBPs) and related proteins (OSBPLs) that share the characteristic OSBP signature, EQVSHHPP [38]. OSBPL proteins play an important role in non-vesicular intracellular transport of lipids, particularly oxysterol, a derivative of cholesterol. OSBPLs serve as sterol sensors and transporters that modulate the lipid composition of cell organelle membranes and assembly of protein complexes, thereby impacting signaling, vesicle transport and lipid metabolism [39].

Osbpl2 was among 132 mRNAs with 3'UTRs predicted to contain potential target sites for miR-96 [32], a microRNA whose mutations cause progressive hearing loss in mice and humans $[32,40]$, but we found no upregulation of Osbpl2 in Mir96 mutant mice (diminuendo) (Additional file 1). However, besides its previously reported expression in the mouse organ of Corti at the onset of hearing [41], there are several lines of evidence that OSBPL2 is the gene underlying ADNSHL in the family described herein: The frameshift mutation c.141_142delTG very likely represents a loss-of-function allele causing OSBPL2 haploinsufficiency. It either results in a truncated non-functional protein of 151 residues 


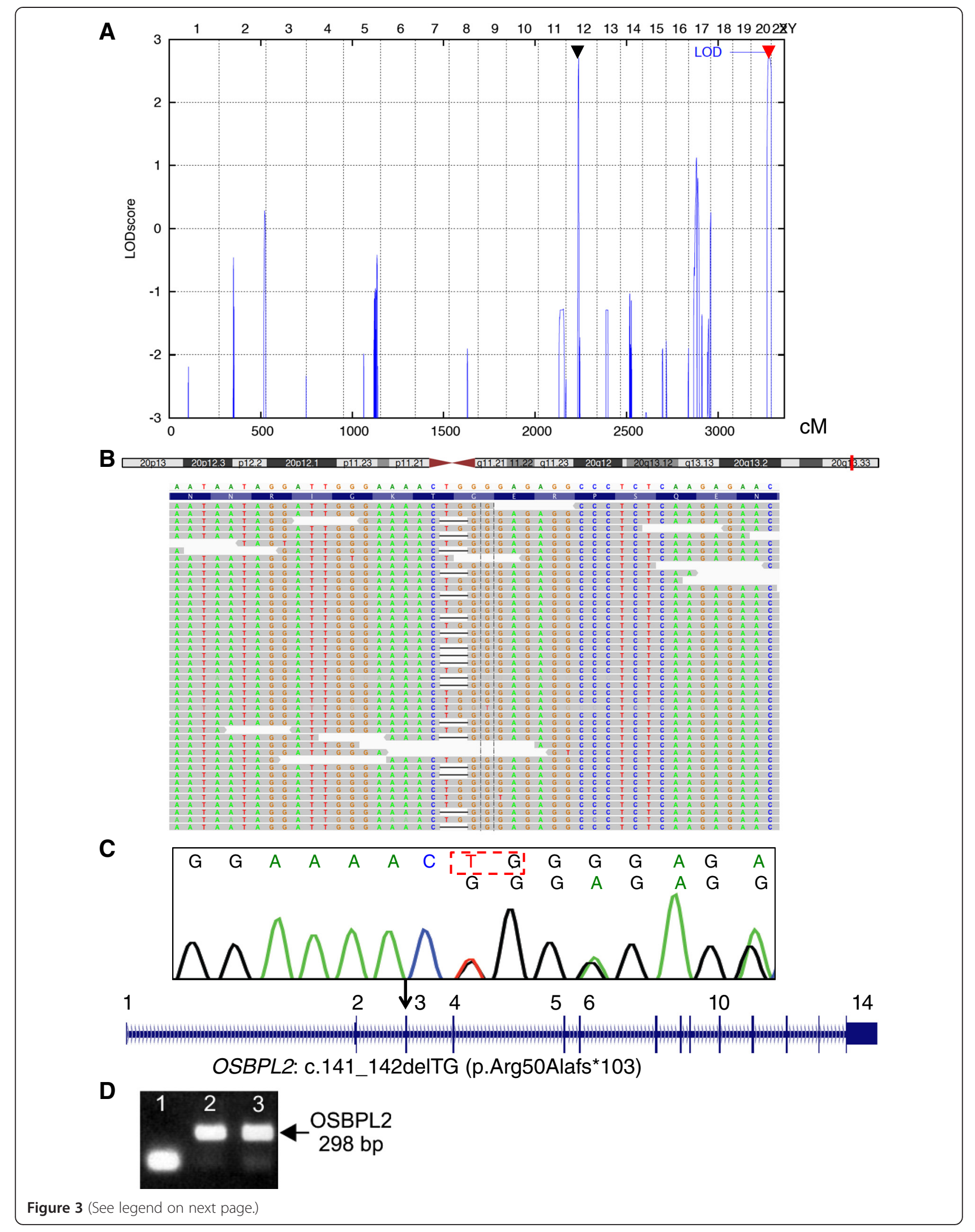


(See figure on previous page.)

Figure 3 Genetics of the German DFNA67 family. A Graphical view of the LOD score calculation of genome-wide SNP mapping. A 3.4 Mb region on chromosome 12 and an $8.4 \mathrm{Mb}$ region on chromosome 20 showed potential linkage with the phenotype. $\mathbf{B}$ Ideogram of chromosome 20 with the position of OSBPL2 indicated (red bar). Schematic representation of the mapped sequencing reads (forward strand) visualized with the Integrative Genomics Viewer (IGV) for patient IV:10. The c.141_142delTG (p.Arg50Alafs*103) mutation in OSBPL2 was present in half of the reads covering this region of the gene. C Electropherogram of a heterozygous carrier of the OSBPL2 mutation in exon 3 (deleted nucleotides are boxed). The localization of the mutation is indicated in a scheme of the OSBPL2 gene. D RT-PCR demonstrates Osbp/2 expression at the transcriptional level in mouse (lane 2) and rat (lane3) cochlea. Lane 1, no cDNA as negative control.

(wild-type: 480 residues) including 102 unrelated amino acids (p.Arg50Alafs*103) or in an unstable mRNA undergoing nonsense-mediated decay. OSBPL2 interacts with diaphanous homologue 1 (DIAPH1) [42], the gene mutated in human ADNSHL type 1 (DFNA1) [43]. DIAPH1 is a Rho effector protein that regulates cytoskeletal dynamics by interacting with actin, microtubules and other proteins associated with cytoskeleton function $[44,45]$. Mutations in DIAPH1 are thought to impair the structural integrity of hair cells' stereocilia, which strongly depends on their actin cytoskeleton, and of the kinocilium, which is built around a microtubular backbone. As is assumed for DIAPH1, OSBPL2 could play a role for the maintenance of hair cells' cytoskeleton, which would be compatible with the prominent presence of OSBPL2 protein at stereocilia (Figure 4). OSBPL2 binds phosphatidylinositol $(3,4,5)$-trisphosphate $\left(\operatorname{PtdIns}(3,4,5) P_{3}\right)[46]$, a phospholipid of the plasma membrane that is crucial for defining neuronal polarity $[47,48]$, a possible hint that OSBPL2 could be needed to establish and maintain polarity of hair cells.
It remains to be determined if the interaction of both proteins is reflected by (at least partial) cellular colocalization.

Of note, an OSBPL2 frameshift mutation in close proximity to the nucleotide position affected by the mutation reported herein has recently been described to co-segregate with ADNSHL in a large Chinese family [49]. Similar to the German DFNA67 family, age of onset was variable (5 to 32 years), and hearing loss was progressive, ranging from mild to profound. This additional DFNA67 family strongly supports the association of OSBPL2 mutations with ADNSHL.

A truncating variant in a gene closely neighboring the chromosome 20 candidate locus, a nonsense mutation in SLC17A9, p.Ser96*, is unlikely to cause hearing loss because it was present in healthy individuals of both our family and our in-house database of 511 epilepsy exomes, and in the general population. SLC17A9 encodes a vesicular nucleotide transporter [50], and heterozygous mutations in this gene have recently been

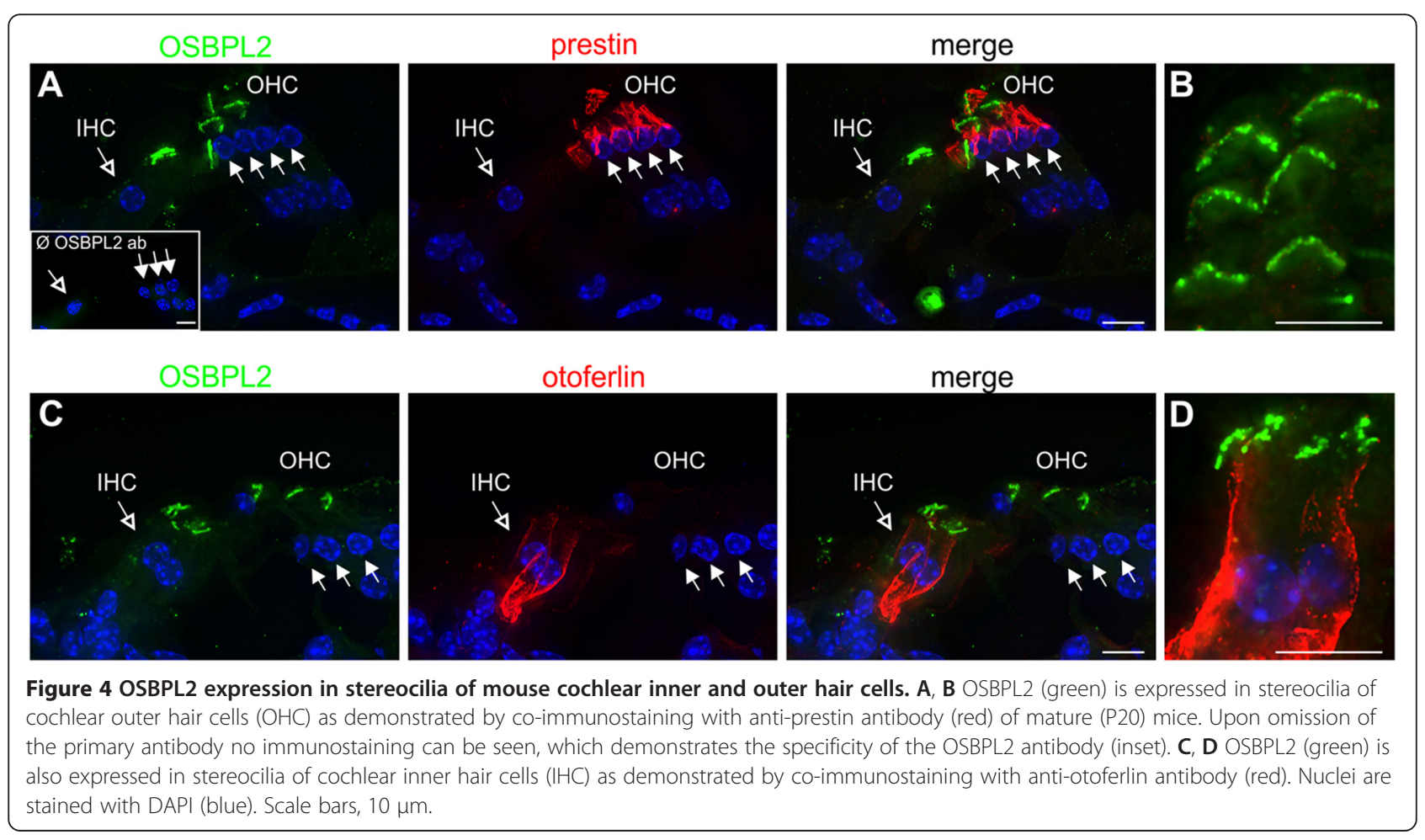


reported to cause disseminated superficial actinic porokeratosis, DSAP [51]. None of the 12 individuals from our DFNA67 family who carried the p.Ser96" ${ }^{\text {SLC17A9 }}$ mutation had any skin abnormalities. In conclusion, SLC17A9 is not only unrelated to hearing loss in this family; its haploinsufficiency does not seem to cause DSAP either. The manifestation of DSAP might thus only result from missense mutations with a dominantnegative effect. On the other hand, our data challenge the assumption that SLC17A9 mutations cause DSAP, and additional research seems necessary to verify the postulated implication of SLC17A9 in skin disease.

\section{Conclusions}

The association of OSBPL2 mutations with ADNSHL indicates a role of lipid metabolism in hair cell function, defining another functional category of proteins involved in hearing loss. However, further research is necessary to clarify how OSBPL2 deficiency causes hearing loss. Other members of the OSBPL family should be considered as potential candidates in future studies aimed at the identification of novel deafness genes.

\section{Additional file}

Additional file 1: Comparison of Osbp/2 mRNA levels between wildtype and homozygous Mir96 mutant diminuendo (Mir96 ${ }^{\text {Dmdo }}$ ) mice. Quantitative real-time PCR on CDNA generated from normalised RNA from the organs of Corti of 4-day-old wildtype (blue) and diminuendo homozygote (red) littermates [32]. Error bars represent standard deviation. Quantities were normalised to Hprt1 levels. No significant difference was observed ( $p=0.083$, Student's $t$-test).

\section{Competing interests}

$T E, C B$ and HJB are employees of Bioscientia, which is part of a publicly traded diagnostic company. The authors declare that they have no competing interests.

\section{Authors' contributions}

$\mathrm{MP}, \mathrm{MMH}, \mathrm{SM}, \mathrm{AG}$ and $\mathrm{HJB}$ carried out the clinical characterization of the family. MT and IE carried out the molecular genetic studies apart from exome sequencing. Targeted NGS was carried out and analyzed by TE, CB and HJB. GN, PN and HT performed linkage analysis, exome sequencing and bioinformatic/statistical analysis. UZ and MK determined localization of OSBPL2 in hair cells. MAL and KPS investigated Osbpl2 expression in diminuendo mice. HJB designed the study and wrote the manuscript. All authors have read and approved the final manuscript.

\section{Acknowledgements}

We are indebted to the family who supported our research enthusiastically. The study was supported by the Geers-Stiftung (to HJB) and the Wellcome Trust (grant no. 100669 to KPS).

\section{Author details}

Institute of Human Genetics, University Hospital of Cologne, Cologne, Germany. ${ }^{2}$ Molecular Physiology of Hearing, Hearing Research Centre Tübingen (THRC), Department of Otolaryngology, University of Tübingen, Tübingen, Germany. ${ }^{3}$ Department of Phoniatrics and Pediatric Audiology, Hannover Medical School, Hannover, Germany. ${ }^{4}$ Wolfson Centre for Age-Related Diseases, King's College London, London, UK. ${ }^{5}$ Cologne Center for Genomics (CCG) and Center for Molecular Medicine Cologne (CMMC), University of Cologne, Cologne, Germany. Institute for Human Genetics,
Hannover Medical School, Hannover, Germany. ${ }^{7}$ Department of Voice, Speech and Hearing Disorders, University Medical Center Hamburg-Eppendorf, Hamburg, Germany. ${ }^{8}$ Department of Human Genetics, University Medical Center Hamburg-Eppendorf, Hamburg, Germany. ${ }^{9}$ Center for Human Genetics, Bioscientia, Ingelheim, Germany. ${ }^{10}$ Renal Division, Department of Medicine, University Medical Center Freiburg, Freiburg, Germany. ${ }^{11}$ Cologne Excellence Cluster on Cellular Stress Responses in Aging-Associated Diseases (CECAD), University of Cologne, Cologne, Germany.

Received: 29 December 2014 Accepted: 3 February 2015

Published online: 10 February 2015

\section{References}

1. Hilgert N, Smith RJ, Van Camp G. Forty-six genes causing nonsyndromic hearing impairment: which ones should be analyzed in DNA diagnostics? Mutat Res. 2009;681:189-96.

2. Parker M, Bitner-Glindzicz M: Genetic investigations in childhood deafness. Arch Dis Child 2014. doi: 10.1136/archdischild-2014-306099

3. Van Camp G, Smith RJH: Hereditary Hearing Loss Homepage. http://hereditaryhearingloss.org 2015.

4. Rehm HL. Disease-targeted sequencing: a cornerstone in the clinic. Nat Rev Genet. 2013;14:295-300.

5. Mazzoli M, Van Camp G, Newton V, Giarbini N, Declau F, Parving A. Recommendations for the description of genetic and audiological data for families with nonsyndromic hereditary hearing impairment. Audiol Med. 2003:1:148-50

6. Eisenberger T, Di Donato N, Baig SM, Neuhaus C, Beyer A, Decker E, et al. Targeted and genomewide NGS data disqualify mutations in MYO1A, the "DFNA48 gene", as a cause of deafness. Hum Mutat. 2014;35:565-70.

7. Li H, Durbin R. Fast and accurate short read alignment with Burrows-Wheeler transform. Bioinformatics. 2009;25:1754-60.

8. Li H, Handsaker B, Wysoker A, Fennell T, Ruan J, Homer N, et al. The Sequence Alignment/Map format and SAMtools. Bioinformatics. 2009;25:2078-9.

9. McKenna A, Hanna M, Banks E, Sivachenko A, Cibulskis K, Kernytsky A, et al. The genome analysis toolkit: a MapReduce framework for analyzing next-generation DNA sequencing data. Genome Res. 2010;20:1297-303.

10. Liu X, Jian X, Boerwinkle E. dbNSFP: a lightweight database of human nonsynonymous SNPs and their functional predictions. Hum Mutat. 2011;32:894-9.

11. Stenson PD, Mort M, Ball EV, Shaw K, Phillips A, Cooper DN. The Human Gene Mutation Database: building a comprehensive mutation repository for clinical and molecular genetics, diagnostic testing and personalized genomic medicine. Hum Genet. 2014;133:1-9.

12. Bamshad MJ, Ng SB, Bigham AW, Tabor HK, Emond MJ, Nickerson DA, et al. Exome sequencing as a tool for Mendelian disease gene discovery. Nat Rev Genet. 2011;12:745-55.

13. Ng PC, Henikoff S. SIFT: Predicting amino acid changes that affect protein function. Nucleic Acids Res. 2003:31:3812-4.

14. Schwarz JM, Rodelsperger C, Schuelke M, Seelow D. MutationTaster evaluates disease-causing potential of sequence alterations. Nat Methods. 2010;7:575-6.

15. Adzhubei I, Jordan DM, Sunyaev SR. Predicting functional effect of human missense mutations using PolyPhen-2. Curr Protoc Hum Genet. 2013; Chapter 7:Unit7 20.

16. Tavtigian SV, Deffenbaugh AM, Yin L, Judkins T, Scholl T, Samollow PB, et al. Comprehensive statistical study of 452 BRCA1 missense substitutions with classification of eight recurrent substitutions as neutral. J Med Genet. 2006:43:295-305

17. Mathe E, Olivier M, Kato S, Ishioka C, Hainaut P, Tavtigian SV. Computational approaches for predicting the biological effect of p53 missense mutations: a comparison of three sequence analysis based methods. Nucleic Acids Res. 2006;34:1317-25

18. Ferrer-Costa C, Gelpi JL, Zamakola L, Parraga I, de la Cruz X, Orozco M. PMUT: a web-based tool for the annotation of pathological mutations on proteins. Bioinformatics. 2005;21:3176-8.

19. Reese MG, Eeckman FH, Kulp D, Haussler D. Improved splice site detection in Genie. J Comput Biol. 1997;4:311-23.

20. Brunak S, Engelbrecht J, Knudsen S. Prediction of human mRNA donor and acceptor sites from the DNA sequence. J Mol Biol. 1991:220:49-65.

21. Hebsgaard SM, Korning PG, Tolstrup N, Engelbrecht J, Rouze P, Brunak S. Splice site prediction in Arabidopsis thaliana pre-mRNA by combining local and global sequence information. Nucleic Acids Res. 1996;24:3439-52. 
22. Abecasis GR, Cherny SS, Cookson WO, Cardon LR. GRR: graphical representation of relationship errors. Bioinformatics. 2001;17:742-3.

23. Gudbjartsson DF, Jonasson K, Frigge ML, Kong A. Allegro, a new computer program for multipoint linkage analysis. Nat Genet. 2000;25:12-3.

24. Thiele H, Nurnberg P. HaploPainter: a tool for drawing pedigrees with complex haplotypes. Bioinformatics. 2005;21:1730-2.

25. Rüschendorf F, Nürnberg P. ALOHOMORA: a tool for linkage analysis using 10 K SNP array data. Bioinformatics. 2005;21:2123-5.

26. Via M, Gignoux C, Burchard EG. The 1000 Genomes Project: new opportunities for research and social challenges. Genome Med. 2010;2:3.

27. Fu W, O'Connor TD, Jun G, Kang HM, Abecasis G, Leal SM, et al. Analysis of 6,515 exomes reveals the recent origin of most human protein-coding variants. Nature. 2013;493:216-20.

28. Heidrych P, Zimmermann U, Kuhn S, Franz C, Engel J, Duncker SV, et al. Otoferlin interacts with myosin VI: implications for maintenance of the basolateral synaptic structure of the inner hair cell. Hum Mol Genet. 2009;18:2779-90.

29. Stefanini M, De Martino C, Zamboni L. Fixation of ejaculated spermatozoa for electron microscopy. Nature. 1967;216:173-4.

30. Weber T, Zimmermann U, Winter H, Mack A, Kopschall I, Rohbock K, et al. Thyroid hormone is a critical determinant for the regulation of the cochlear motor protein prestin. Proc Natl Acad Sci U S A. 2002;99:2901-6.

31. Schug N, Braig C, Zimmermann U, Engel J, Winter $H$, Ruth $P$, et al. Differential expression of otoferlin in brain, vestibular system, immature and mature cochlea of the rat. Eur J Neurosci. 2006;24:3372-80.

32. Lewis MA, Quint E, Glazier AM, Fuchs H, De Angelis MH, Langford C, et al. An ENU-induced mutation of miR-96 associated with progressive hearing loss in mice. Nat Genet. 2009:41:614-8.

33. Morrison A, Hodgetts C, Gossler A, Hrabe de Angelis M, Lewis J. Expression of Delta1 and Serrate1 (Jagged1) in the mouse inner ear. Mech Dev. 1999;84:169-72.

34. Zine A, Van De Water TR, de Ribaupierre F. Notch signaling regulates the pattern of auditory hair cell differentiation in mammals. Development. 2000;127:3373-83

35. Mims MP, Guan Y, Pospisilova D, Priwitzerova M, Indrak K, Ponka P, et al. Identification of a human mutation of DMT1 in a patient with microcytic anemia and iron overload. Blood. 2005;105:1337-42.

36. Talas U, Dunlop J, Khalaf S, Leigh IM, Kelsell DP. Human elastase 1: evidence for expression in the skin and the identification of a frequent frameshift polymorphism. J Invest Dermatol. 2000;114:165-70.

37. Futterer A, Campanero MR, Leonardo E, Criado LM, Flores JM, Hernandez $J M$, et al. Dido gene expression alterations are implicated in the induction of hematological myeloid neoplasms. J Clin Invest. 2005;115:2351-62.

38. Jaworski CJ, Moreira E, Li A, Lee R, Rodriguez IR. A family of 12 human genes containing oxysterol-binding domains. Genomics. 2001:78:185-96.

39. Olkkonen VM. OSBP-related proteins: liganding by glycerophospholipids opens new insight into their function. Molecules. 2013;18:13666-79.

40. Mencia A, Modamio-Hoybjor S, Redshaw N, Morin M, Mayo-Merino F, Olavarrieta $L$, et al. Mutations in the seed region of human miR-96 are responsible for nonsyndromic progressive hearing loss. Nat Genet. 2009:41:609-13.

41. Pompeia C, Hurle B, Belyantseva IA, Noben-Trauth K, Beisel K, Gao J, et al Gene expression profile of the mouse organ of Corti at the onset of hearing. Genomics. 2004:83:1000-11.

42. Li D, Dammer EB, Lucki NC, Sewer MB. CAMP-stimulated phosphorylation of diaphanous 1 regulates protein stability and interaction with binding partners in adrenocortical cells. Mol Biol Cell. 2013;24:848-57.

43. Lynch ED, Lee MK, Morrow JE, Welcsh PL, Leon PE, King MC. Nonsyndromic deafness DFNA1 associated with mutation of a human homolog of the Drosophila gene diaphanous. Science. 1997;278:1315-8.

44. Bartolini F, Gundersen GG. Formins and microtubules. Biochim Biophys Acta. 1803;2010:164-73.

45. Copeland JW, Treisman R. The diaphanous-related formin mDia1 controls serum response factor activity through its effects on actin polymerization. Mol Biol Cell. 2002;13:4088-99.

46. Hynynen R, Laitinen S, Kakela R, Tanhuanpaa K, Lusa S, Ehnholm C, et al Overexpression of OSBP-related protein 2 (ORP2) induces changes in cellular cholesterol metabolism and enhances endocytosis. Biochem J. 2005:390:273-83.

47. Pinal N, Goberdhan DC, Collinson L, Fujita Y, Cox IM, Wilson C, et al. Regulated and polarized Ptdlns(3,4,5)P3 accumulation is essential for apical membrane morphogenesis in photoreceptor epithelial cells. Curr Biol. 2006:16:140-9.

48. Shi SH, Jan LY, Jan YN. Hippocampal neuronal polarity specified by spatially localized mPar3/mPar6 and PI 3-kinase activity. Cell. 2003;112:63-75.

49. Xing G, Yao J, Wu B, Liu T, Wei Q, Liu C, et al.: Identification of OSBPL2 as a novel candidate gene for progressive nonsyndromic hearing loss by whole-exome sequencing. Genet Med 2014 doi:10.1038/gim.2014.90

50. Sawada K, Echigo N, Juge N, Miyaji T, Otsuka M, Omote $H$, et al Identification of a vesicular nucleotide transporter. Proc Natl Acad Sci U S A. 2008;105:5683-6.

51. Cui H, Li L, Wang W, Shen J, Yue Z, Zheng X, et al. Exome sequencing identifies SLC17A9 pathogenic gene in two Chinese pedigrees with disseminated superficial actinic porokeratosis. J Med Genet. 2014;51:699-704.

\section{Submit your next manuscript to BioMed Central and take full advantage of:}

- Convenient online submission

- Thorough peer review

- No space constraints or color figure charges

- Immediate publication on acceptance

- Inclusion in PubMed, CAS, Scopus and Google Scholar

- Research which is freely available for redistribution 